Hydrogen sulfide postconditioning protects isolated rat hearts against ischemia and reperfusion injury mediated by the JAK2/STAT3 survival pathway

Heng-Fei Luan, Zhi-Bin Zhao, Qi-Hong Zhao, Pin Zhu, Ming-Yu Xiu and Yong Ji

The Brazilian Journal of Medical and Biological Research is partially financed by

\section{贵CNPq}

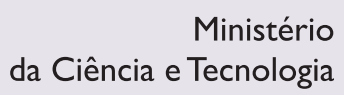

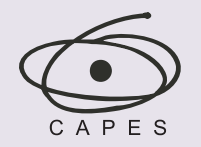

Ministério da Educação
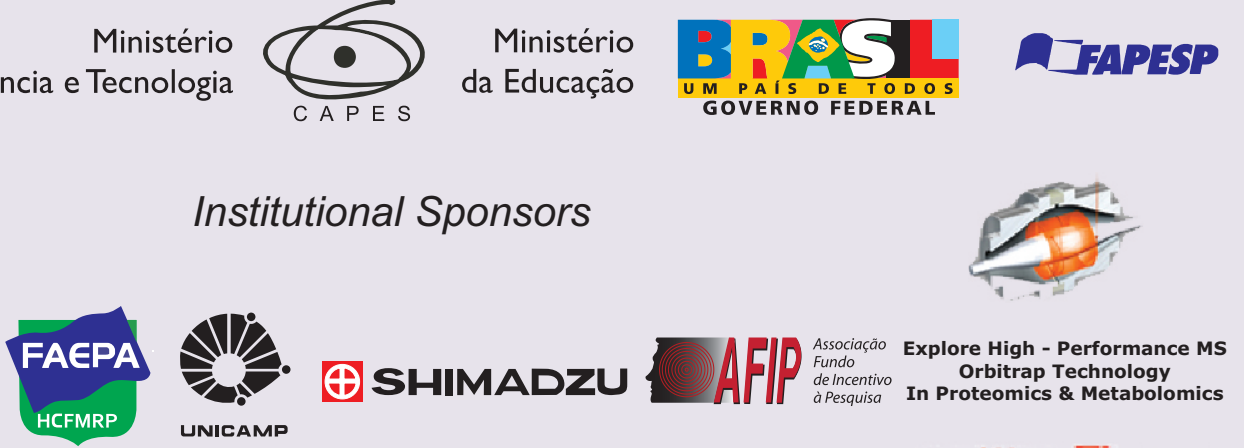

Institutional Sponsors
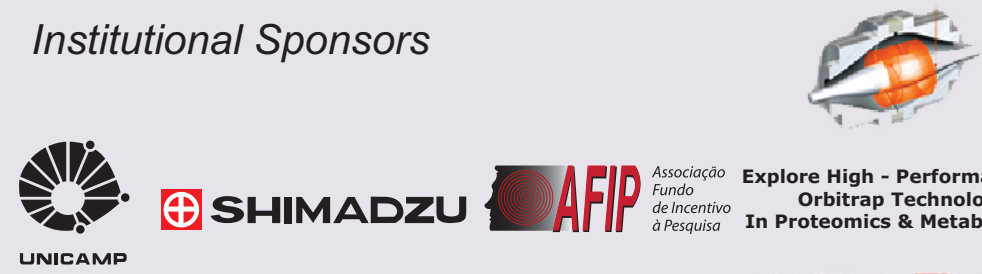

Ф SHIMADZU UNICAMP

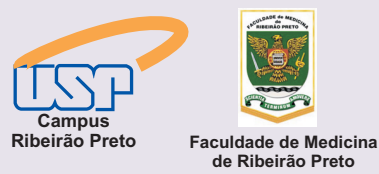

de Ribeirão Preto 


\title{
Hydrogen sulfide postconditioning protects isolated rat hearts against ischemia and reperfusion injury mediated by the JAK2/STAT3 survival pathway
}

\author{
Heng-Fei Luan ${ }^{1 *}$, Zhi-Bin Zhao ${ }^{1 *}$, Qi-Hong Zhao ${ }^{2}$, Pin Zhu ${ }^{1}$, Ming-Yu Xiu ${ }^{1}$ and Yong Ji ${ }^{3}$ \\ ${ }^{1}$ Department of Anesthesiology, The First People's Hospital of Lianyungang, Lianyungang, Jiangsu, China \\ ${ }^{2}$ Department of Anesthesiology, The First Affiliated Hospital of Bengbu Medical College, Bengbu, Anhui, China \\ ${ }^{3}$ Department of Anesthesiology, Wuxi No. 4 People's Hospital, The Fourth Affiliated Hospital of Soochow University, \\ Wuxi, Jiangsu, China
}

\begin{abstract}
The JAK2/STAT3 signal pathway is an important component of survivor activating factor enhancement (SAFE) pathway. The objective of the present study was to determine whether the JAK2/STAT3 signaling pathway participates in hydrogen sulfide $\left(\mathrm{H}_{2} \mathrm{~S}\right)$ postconditioning, protecting isolated rat hearts from ischemic-reperfusion injury. Male Sprague-Dawley rats (230-270 g) were divided into 6 groups ( $\mathrm{N}=14$ per group): time-matched perfusion (Sham) group, ischemia/reperfusion (I/R) group, NaHS postconditioning group, NaHS with AG-490 group, AG-490 (5 $\mu \mathrm{M})$ group, and dimethyl sulfoxide (DMSO; <0.2\%) group. Langendorff-perfused rat hearts, with the exception of the Sham group, were subjected to 30 min of ischemia followed by 90 min of reperfusion after 20 min of equilibrium. Heart rate, left ventricular developed pressure (LVDP), left ventricular end-diastolic pressure (LVEDP), and the maximum rate of increase or decrease of left ventricular pressure $\left( \pm \mathrm{dp} / \mathrm{dt}_{\text {max }}\right)$ were recorded. Infarct size was determined using triphenyltetrazolium chloride (TTC) staining. Myocardial TUNEL staining was used as the in situ cell death detection method and the percentage of TUNEL-positive nuclei to all nuclei counted was used as the apoptotic index. The expression of STAT3, bcl-2 and bax was determined by Western blotting. After reperfusion, compared to the $\mathrm{I} / \mathrm{R}$ group, $\mathrm{H}_{2} \mathrm{~S}$ significantly improved functional recovery and decreased infarct size $(23.3 \pm 3.8$ vs $41.2 \pm 4.7 \%, P<0.05)$ and apoptotic index $(22.1 \pm 3.6$ vs $43.0 \pm 4.8 \%, P<$ 0.05). However, $\mathrm{H}_{2} \mathrm{~S}$-mediated protection was abolished by AG-490, the JAK2 inhibitor. In conclusion, $\mathrm{H}_{2} \mathrm{~S}$ postconditioning effectively protects isolated I/R rat hearts via activation of the JAK2/STAT3 signaling pathway.
\end{abstract}

Key words: Hydrogen sulfide; JAK2/STAT3; Apoptosis; Postconditioning; Ischemia/reperfusion injury

\section{Introduction}

Acute myocardial infarction has become the leading cause of morbidity and mortality in the world. Re-establishing coronary blood flow with the rapid use of reperfusion strategies such as thrombolysis, percutaneous coronary angioplasty and coronary artery bypass graft are essential to salvage viable myocardium. However, reperfusion itself may result in damage to ischemic myocardial tissue, which is known as "reperfusion injury" (1). Thus, finding an effective way to reduce reperfusion injury has become a significant area of research in the field of cardioprotection. In 2003, Zhao et al. (2) first proposed that ischemic postconditioning (IPO), whereby brief episodes of ischemia/ reperfusion are applied at the onset of reperfusion, could limit reperfusion injury by activation of intrinsic prosurvival signaling cascades.

The Janus kinase-signal transducer and activator of transcription (JAK-STAT) pathway is an important intracellular signaling pathway, which can transduce cellular signals from the plasma membrane to the nucleus, resulting in the regulation of gene expression. The JAK-STAT pathway has been shown to play an important role in multiple processes within the heart $(3,4)$, including hypertrophy $(5,6)$, apoptosis $(7,8)$, ischemia-reperfusion $(I / R)$ injury $(9,10)$, preconditioning (11), and postconditioning (12). Previous studies about the mechanism of cardioprotection offered by postconditioning have focused mainly on the reperfusion injury salvage kinases (RISK) pathway, which includes prosurvival kinase Akt and extracellular regulated kinase 1/2 (ERK1/2) (13),

Correspondence: Yong Ji, Department of Anesthesiology, Wuxi No. 4 People's Hospital, The Fourth Affiliated Hospital of Soochow University, Wuxi, 214000 Jiangsu, China. Fax: +86-510-8868-2225. E-mail: jy6941@yahoo.com.cn

*These authors contributed equally to this study.

Received October 30, 2011. Accepted May 11, 2012. Available online June 1, 2012. Published September 3, 2012. 
However, recent studies have demonstrated that protection offered by IPO could occur independently of the activation of the RISK pathway, therefore confirming the existence of multiple protective pathways $(14,15)$. In 2009, Lecour (16) first reported that, in addition to the RISK pathway, the survivor activating factor enhancement (SAFE) pathway should be an alternative pathway involved in IPO-activated signaling events.

$\mathrm{H}_{2} \mathrm{~S}$ is now recognized as a novel gaseous transmitter together with nitric oxide and carbon monoxide. In the heart, $\mathrm{H}_{2} \mathrm{~S}$ is produced in the myocardium, fibroblasts and blood vessels from $L$-cysteine by the enzyme cystathionine $Y$-lyase (CSE) and exerts an important effect on physiology and pathophysiology processes (17). Convincing evidence has shown that $\mathrm{H}_{2} \mathrm{~S}$ has a negative inotropic effect on the heart and regulates vascular tone by opening ATP-sensitive $\mathrm{K}^{+}$ (K $\mathrm{K}_{\text {ATP }}$ ) channels (18). Previous studies have demonstrated that PI3K/Akt, ERK1/2 (19), and protein kinase C (PKC) (20) mediate the cardioprotection offered by $\mathrm{H}_{2} \mathrm{~S}$ preconditioning. These various actions highlight the potential importance of endogenous $\mathrm{H}_{2} \mathrm{~S}$ for the physiological regulations of cardiovascular system function. Whether the JAK2/STAT3 signaling pathway participates in $\mathrm{H}_{2} \mathrm{~S}$ postconditioning protecting isolated rat hearts against I/R injury is unknown. In the present study, we blocked the JAK2/STAT3 signaling pathway with AG-490 (a specific inhibitor of JAK2) to determine if the JAK2/STAT3 signaling pathway participates in the cardioprotection of $\mathrm{H}_{2} \mathrm{~S}$ postconditioning.

\section{Material and Methods}

\section{Material}

All animal care and experimental protocols complied with the guidelines of the Animal Care and Use Committee of the University of Xuzhou Medical College. Adult, male Sprague-Dawley rats weighing 230-270 g were provided by the Experimental Animal Center of Xuzhou Medical College (Xuzhou, China). Rats were maintained in an air-filtered, temperature-conditioned (20-22) and light-controlled (12-h light/dark cycle) room with a relative humidity of $50-52 \%$. Rats had free access to standard commercial pellets and water.

\section{Isolated, perfused heart preparation}

Sprague-Dawley rats (230-270 g) were anesthetized with sodium pentobarbital $(60 \mathrm{mg} / \mathrm{kg})$ and anticoagulated with an intraperitoneal injection of heparin (500 IU/kg). After a midline sternotomy, the hearts were rapidly excised and perfused retrogradely at a constant perfusion pressure of $100 \mathrm{cmH}_{2} \mathrm{O}(\approx 75 \mathrm{mmHg})$ with a modified Krebs-Hanseleit (K-H) buffer containing $118.5 \mathrm{mM} \mathrm{NaCl}$, 24.8 $\mathrm{mM} \mathrm{NaHCO}_{3}, 11 \mathrm{mM} \mathrm{D}$-glucose, $4.7 \mathrm{mM} \mathrm{KCl}, 1.2 \mathrm{mM}$ $\mathrm{MgSO}_{4} \cdot 7 \mathrm{H}_{2} \mathrm{O}, 1.2 \mathrm{mM} \mathrm{KH}_{2} \mathrm{PO}_{4}, 2.25 \mathrm{mM} \mathrm{CaCl}_{2} \cdot 2 \mathrm{H}_{2} \mathrm{O}$, $\mathrm{pH}$ 7.4. The perfusate buffer was saturated with a $95 \%$ $\mathrm{O}_{2}$ and $5 \% \mathrm{CO}_{2}$ gas mixture at $37^{\circ} \mathrm{C}$ before use. A latex balloon was inserted into the left ventricle via the left atrium, inflated with distilled water and then connected to the Maclab System (Maclab, AD Instruments Ltd., USA). The left ventricular end-diastolic pressure (LVEDP) was set between 4 and $7 \mathrm{mmHg}$. The balloon volume remained unchanged for the rest of the experiment. The left ventricular function index was monitored continuously with a computer-based system for the acquisition of data regarding LVEDP, left ventricular developed pressure (LVDP), positive and negative LV dp/dt $\left(+d p / d t_{\max },-d p /\right.$ $\left.\mathrm{dt}_{\max }\right)$, and heart rate (HR). Before each experimental protocol was initiated, the isolated hearts were allowed to stabilize at $37^{\circ} \mathrm{C}$ for $20 \mathrm{~min}$. Hearts were excluded from further study if after stabilization they failed to develop steady sinus rhythm or their LVDPs were less than $50 \mathrm{mmHg}$.

\section{Experimental protocol}

The whole procedure lasted $140 \mathrm{~min}$. After equilibration for $20 \mathrm{~min}$, the isolated heart underwent 30-min of global ischemia followed by $90 \mathrm{~min}$ of reperfusion. Rats were randomly divided into 6 groups as follows $(N=84,14$ per group; Figure 1): 1) Sham group = perfusion for $140 \mathrm{~min}$ in $\mathrm{K}-\mathrm{H}$ buffer; 2) I/R group = global ischemia (reperfusion rate $=0 \mathrm{~mL} / \mathrm{min}$ ) for $30 \mathrm{~min}$ and then $90 \mathrm{~min}$ of reperfusion; 3) sodium hydrosulfide (NaHS) postconditioning group = four cycles of NaHS postconditioning (15 s of reperfusion with $\mathrm{K}-\mathrm{H}$ buffer containing $10 \mu \mathrm{M}$ NaHS followed by $15 \mathrm{~s}$ of reperfusion with $\mathrm{K}-\mathrm{H}$ buffer) at the onset of reperfusion; 4) $\mathrm{NaHS}+\mathrm{AG}-490$ group = in addition to $\mathrm{NaHS}$ postconditioning, administration of the selective JAK2 inhibitor AG$490(5 \mu \mathrm{M})$ in DMSO for $10 \mathrm{~min}$ at the end of equilibration and 5 min at the onset of reperfusion; 5) AG-490 group = administration of $5 \mu \mathrm{M} \mathrm{AG}-490$ in DMSO for $10 \mathrm{~min}$ at the end of equilibration and $5 \mathrm{~min}$ at the onset of reperfusion; 6) $\mathrm{DMSO}$ group = administration of the AG-490 vehicle DMSO $(<0.2 \%)$ for $10 \mathrm{~min}$ at the end of equilibration and $5 \mathrm{~min}$ at the onset of reperfusion.

\section{Determination of myocardial infarct size}

At the end of the experiment, the hearts were frozen at $-20^{\circ} \mathrm{C}$ for $2 \mathrm{~h}$ and then thawed and cut into 2-mm transverse slices. After incubation with $1 \%$ tetrazolium chloride (TTC) in PBS, pH 7.4, for $30 \mathrm{~min}\left(37^{\circ} \mathrm{C}\right)$, the sections were fixed for $10-14 \mathrm{~h}$ in $10 \%$ formaldehyde. The slices were then photographed with a digital camera and the pictures were fed into a computer. Total area and infarct area were determined by computerized planimetry (Adobe Photoshop, version 7.0). The infarct size was expressed as a percentage of total ventricular area $(\%)$.

\section{Apoptosis assay}

Cardiomyocyte apoptosis was assessed by the terminal deoxynucleotidyl transferase-mediated dUTP-biotin nickend labeling (TUNEL) assay. Briefly, apoptotic cells were 
identified using an in situ cell death detection kit (Roche, Germany) following manufacturer instructions. Nuclei with brown staining indicated TUNEL-positive cells. Eighteen randomly selected fields ( 6 hearts per group, three fields per heart) were observed for each group. The apoptotic index (AI), or the percentage of apoptotic nuclei (TUNEL-positive) vs total number of nuclei was determined.

\section{Western blot analysis}

The left ventricular tissue was taken and immediately frozen in liquid nitrogen at $-70^{\circ} \mathrm{C}$ after 90 min of reperfusion. Tissues were homogenized with a Teflon-glass homogenizer in 1:10 (w/v) ice-cold homogenization buffer consisting of $50 \mathrm{mM} 3$-(N-morpholino) propanesulfonic acid (MOPS), pH 7.4, 50 mM NaF, 20 mM NaPPi, 20 mM $\beta$-glycerophosphate, $1 \mathrm{mM}$ EDTA, $1 \mathrm{mM}$ EGTA, $1 \mathrm{mM}$ phenylmethyl sulfonyl fluoride, $10 \mu \mathrm{g} / \mathrm{mL}$ leupeptin, 10 $\mu \mathrm{g} / \mathrm{mL}$ aprotin, and $10 \mu \mathrm{g} / \mathrm{mL}$ pepstatin A. This step was followed by centrifugation at $800 \mathrm{~g}$ for $15 \mathrm{~min}$ at $4^{\circ} \mathrm{C}$ and the supernatants were used. The nuclear pellets were extracted with extraction buffer containing $20 \mathrm{mM} \mathrm{HEPES}$, $\mathrm{pH} 7.9,20 \%$ glycerol, $420 \mathrm{mM} \mathrm{NaCl}, 0.5 \mathrm{mM} \mathrm{MgCl}_{2}, 1 \mathrm{mM}$ EDTA, $1 \mathrm{mM}$ EGTA, $1 \mathrm{mM}$ DTT, and enzyme inhibitors for 30 min at $4^{\circ} \mathrm{C}$ with constant shaking. After centrifugation at $15,000 \mathrm{~g}$ for $15 \mathrm{~min}$ at $4^{\circ} \mathrm{C}$, supernatants containing nuclear proteins were collected and samples were stored at $-80^{\circ} \mathrm{C}$ until use. The protein concentrations were determined by the method of Lowry et al. (21) with bovine serum albumin as standard. After the determination of protein concentration, $100 \mu \mathrm{g}$ protein of each sample was denatured at $100^{\circ} \mathrm{C}$ for 5 min with SDS-PAGE sample loading buffer and then separated by SDS-PAGE using $10-15 \%$ acrylamide gels, and transferred to nitrocellulose membranes. The membranes were incubated overnight at $4^{\circ} \mathrm{C}$ with the primary antibody, washed three times with Tris-buffered saline Tween-20 for 5 min each time, and incubated for $2 \mathrm{~h}$ with the secondary antibody conjugated with alkaline phosphatase at room temperature. Immune complexes were detected using an NBT/BCIP assay kit. The scanned images were imported into Adobe Photoshop software (Adobe, USA). Scanning densitometry was used for semiquantitative analysis.

\section{Reagents}

NaHS and TTC were purchased from Sigma-Aldrich Company Ltd. (USA). Anti-STAT3 (No. 21045-1) and anti-phospho-STAT3 (No. 11045-1) antibodies were obtained from Signalway Antibody (USA). Anti-bcl-2 (SC-492) and anti-bax (SC-526-a) antibodies were obtained from Santa Cruz Biotechnology (USA). Cell death detection kits for apoptosis assay were purchased from Roche, and the sec- ondary antibody conjugated with alkaline phosphatase was purchased from Zhongshan Goldenbridge Biotechnoiogy (China). AG-490, SDS-PAGE sample loading buffer (5X), SDS-PAGE gel preparation kit and BCIP/NBT 5-bromo-4chloro-3-indolyl phosphate/nitroblue tetrazolium alkaline phosphatase color development kit were all purchased from Beyotime Institute of Biotechnology (China).

\section{Statistical analysis}

Data are reported as means \pm SD. For hemodynamic data, repeated-measures analysis of variance was used to evaluate differences over time between groups. The unpaired $t$-test was used to compare groups at identical time points, and the paired $t$-test was used to compare data within groups over time. For all other data, one-way analysis of variance was used, followed by the post hoc Tukey test for multiple comparisons. $\mathrm{P}<0.05$ was considered to be statistically significant. All statistical analyses were performed using the SPSS 13.0 software (SPSS Inc., USA).

\section{Results}

\section{Effect of NaHS postconditioning on systemic hemodynamics}

No differences in baseline hemodynamics were observed among the experimental groups $(P>0.05)$. At 30,60 , and 90 min of reperfusion, with the exception of the Sham group, all other groups showed a significant decrease $(P<0.05)$ in $H R$, $+\mathrm{dp} / \mathrm{dt}$, $-\mathrm{dp} / \mathrm{dt}$, and LVDP, and a large increase $(P<0.05)$ in LVEDP compared to baseline values. All experimental groups showed a significant decrease $(P<0.05)$ in $H R$, $+d p / d t$, -dp/dt, and LVDP, and a large increase $(P<0.05)$ in LVEDP compared to the Sham group. Compared to the I/R group, the NaHS group showed a significant increase $(P<0.05)$ in $\mathrm{HR},+\mathrm{dp} / \mathrm{dt}_{\max },-\mathrm{dp} / \mathrm{dt}_{\max }$, and LVDP, and a large decrease

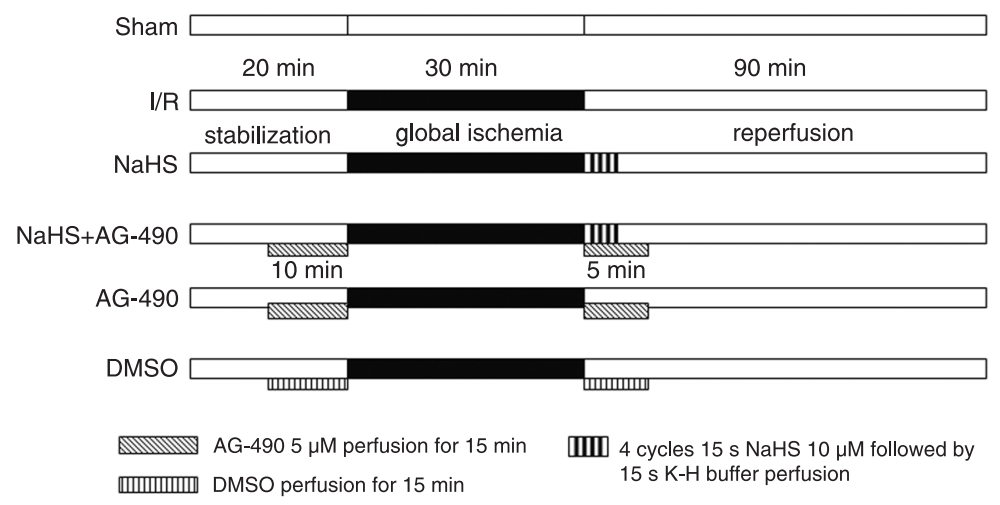

Figure 1. Schematic diagram depicting the experimental protocol $(N=14)$. Sham = Time-matched reperfusion; $\mathrm{I} / \mathrm{R}=$ ischemia/reperfusion; $\mathrm{NaHS}$ = sodium hydrosulfide postconditioning; AG-490 $=$ specific inhibitor of JAK2; DMSO = dimethyl sulfoxide. 
$(P<0.05)$ in LVEDP. There was no significant difference in the NaHS+AG-490, AG-490, DMSO, and I/R groups (Table 1).

\section{Effect of NaHS postconditioning on myocardial infarct size}

As shown in Figure 2, infarct size was significantly reduced in the $\mathrm{NaHS}$ group $(23.3 \pm 3.8 \%, \mathrm{P}<0.05)$ compared to the I/R group (41.2 $\pm 4.7 \%$ ) at the end of reperfusion. Infarct size was $37.1 \pm 5.2,41.7 \pm 4.1$, and $40.1 \pm$ $5.8 \%$ in the NaHS+AG-490, AG-490, and DMSO groups, respectively, with no significant differences compared to the I/R group $(P>0.05)$.

\section{Effect of NaHS postconditioning on apoptosis}

Figure 3 shows that the Al was $10.1 \pm 2.6,43.0 \pm 4.8,22.1 \pm 3.6,40.5$ $\pm 4.5,39.6 \pm 5.2$, and $41.1 \pm 4.1 \%$ in the Sham, I/R, NaHS, NaHS+AG-490, AG-490, and DMSO groups, respectively, with the values for the various groups being significantly increased compared to the Sham group $(\mathrm{P}<$ 0.05). Compared to the I/R group, Al was obviously decreased in the NaHS group $(P<0.05)$; compared to the NaHS group, $\mathrm{Al}$ was increased in the DMSO, AG-490, NaHS+AG-490 groups $(P<0.05)$.

\section{Effect of NaHS postconditioning on the expression of p-STAT3, bcl-2 and bax}

As illustrated in Figure 4, Western blotting showed the phosphorylated state of STAT3 (Tyr 705) at the end of reperfusion. Compared to the Sham group, the expression of p-STAT3 was significantly increased in the $\mathrm{I} / \mathrm{R}$ group $(P<0.05)$. Compared to the $I / R$ group, the expression of p-STAT3 was further increased in the NaHS group $(P<0.05)$. Compared with the NaHS group, the expression of p-STAT3 in the NaHS+AG-490 and AG-490 groups was decreased (P $<0.05)$. There were no statistical differences between the DMSO and I/R groups.

Compared to the Sham group, bcl-2 was decreased and bax was increased in the other groups $(P<0.05)$. Compared to the I/R group, bcl-2 was increased and bax
Table 1. Left ventricular hemodynamics.

\begin{tabular}{|c|c|c|c|c|}
\hline \multirow[t]{2}{*}{ Group } & \multirow[t]{2}{*}{ Baseline } & \multicolumn{3}{|c|}{ Reperfusion } \\
\hline & & $30 \mathrm{~min}$ & $60 \mathrm{~min}$ & $90 \mathrm{~min}$ \\
\hline \multicolumn{5}{|l|}{ HR (bpm) } \\
\hline Sham & $269 \pm 11$ & $262 \pm 19$ & $260 \pm 18$ & $261 \pm 19$ \\
\hline $\mathrm{I} / \mathrm{R}$ & $263 \pm 12$ & $201 \pm 20^{\star+}$ & $207 \pm 28^{*+}$ & $210 \pm 26^{\star+}$ \\
\hline $\mathrm{NaHS}$ & $269 \pm 13$ & $238 \pm 19^{*+\#}$ & $241 \pm 18^{*+\#}$ & $240 \pm 20^{\star+\#}$ \\
\hline $\mathrm{NaHS}+\mathrm{AG}-490$ & $276 \pm 15$ & $211 \pm 20^{\star+}$ & $218 \pm 18^{*+}$ & $220 \pm 19^{\star+}$ \\
\hline AG-490 & $272 \pm 16$ & $206 \pm 17^{\star+}$ & $212 \pm 15^{\star+}$ & $215 \pm 16^{\star+}$ \\
\hline DMSO & $264 \pm 20$ & $210 \pm 14^{*+}$ & $214 \pm 11^{*+}$ & $220 \pm 13^{*+}$ \\
\hline \multicolumn{5}{|l|}{ LVEDP $(\mathrm{mmHg})$} \\
\hline Sham & $5.0 \pm 0.6$ & $5.4 \pm 0.7$ & $5.2 \pm 0.7$ & $5.3 \pm 0.6$ \\
\hline I/R & $4.9 \pm 0.4$ & $33.1 \pm 7.3^{\star+}$ & $34.2 \pm 7.3^{*+}$ & $33.3 \pm 7.1^{*+}$ \\
\hline $\mathrm{NaHS}$ & $5.0 \pm 0.5$ & $26.7 \pm 6.1^{*+\#}$ & $24.2 \pm 6.4^{*+\#}$ & $25.1 \pm 6.3^{\star+\#}$ \\
\hline $\mathrm{NaHS}+\mathrm{AG}-490$ & $5.2 \pm 0.5$ & $35.6 \pm 5.5^{\star+}$ & $35.3 \pm 6.1^{*+}$ & $36.0 \pm 5.9^{\star+}$ \\
\hline AG-490 & $4.9 \pm 0.5$ & $32.0 \pm 5.1^{*+}$ & $32.4 \pm 5.9^{\star+}$ & $32.5 \pm 5.8^{\star+}$ \\
\hline DMSO & $5.1 \pm 0.6$ & $33.1 \pm 6.5^{\star+}$ & $35.2 \pm 6.2^{*+}$ & $34.5 \pm 6.0^{\star+}$ \\
\hline \multicolumn{5}{|l|}{ LVDP (mmHg) } \\
\hline Sham & $102 \pm 10$ & $98 \pm 8$ & $99 \pm 7$ & $100 \pm 9$ \\
\hline $\mathrm{l} / \mathrm{R}$ & $103 \pm 9$ & $56 \pm 7^{*+}$ & $57 \pm 9^{*+}$ & $57 \pm 10^{\star+}$ \\
\hline $\mathrm{NaHS}$ & $97 \pm 7$ & $73 \pm 12^{\star+\#}$ & $75 \pm 12^{\star+\#}$ & $74 \pm 11^{\star+\#}$ \\
\hline $\mathrm{NaHS}+\mathrm{AG}-490$ & $99 \pm 8$ & $60 \pm 9^{*+}$ & $59 \pm 9^{*+}$ & $60 \pm 9^{*+}$ \\
\hline AG-490 & $101 \pm 11$ & $61 \pm 10^{*+}$ & $62 \pm 10^{*+}$ & $61 \pm 9^{*+}$ \\
\hline DMSO & $97 \pm 8$ & $58 \pm 9^{*+}$ & $58 \pm 10^{*+}$ & $60 \pm 10^{*+}$ \\
\hline \multicolumn{5}{|c|}{$+\mathrm{dp} / \mathrm{dt}_{\max }(\mathrm{mmHg} / \mathrm{s})$} \\
\hline Sham & $2731 \pm 228$ & $2810 \pm 180$ & $2791 \pm 181$ & $2800 \pm 179$ \\
\hline $\mathrm{I} / \mathrm{R}$ & $2829 \pm 239$ & $1205 \pm 240^{*+}$ & $1220 \pm 236^{*+}$ & $1219 \pm 230^{\star+}$ \\
\hline $\mathrm{NaHS}$ & $2790 \pm 184$ & $1737 \pm 177^{\star+\#}$ & $1786 \pm 180^{*+\#}$ & $1801 \pm 191^{*+\#}$ \\
\hline $\mathrm{NaHS}+\mathrm{AG}-490$ & $2780 \pm 235$ & $1136 \pm 263^{*+}$ & $1135 \pm 272^{*+}$ & $1152 \pm 268^{*+}$ \\
\hline AG-490 & $2858 \pm 302$ & $1223 \pm 235^{\star+}$ & $1226 \pm 247^{\star+}$ & $1220 \pm 233^{\star+}$ \\
\hline DMSO & $2845 \pm 182$ & $1180 \pm 213^{*+}$ & $1195 \pm 204^{*+}$ & $1201 \pm 211^{*+}$ \\
\hline \multicolumn{5}{|c|}{$-\mathrm{dp} / \mathrm{dt}_{\max }(\mathrm{mmHg} / \mathrm{s})$} \\
\hline Sham & $2098 \pm 191$ & $2014 \pm 192$ & $2068 \pm 183$ & $2072 \pm 181$ \\
\hline I/R & $2003 \pm 197$ & $892 \pm 195^{\star+}$ & $895 \pm 190^{\star+}$ & $890 \pm 191^{*+}$ \\
\hline $\mathrm{NaHS}$ & $2001 \pm 264$ & $1305 \pm 204^{\star+\#}$ & $1314 \pm 200^{*+\#}$ & $1318 \pm 201^{*+\#}$ \\
\hline $\mathrm{NaHS}+\mathrm{AG}-490$ & $2133 \pm 168$ & $940 \pm 176^{*+}$ & $938 \pm 181^{*+}$ & $945 \pm 177^{*+}$ \\
\hline AG-490 & $1998 \pm 250$ & $952 \pm 203^{*+}$ & $946 \pm 205^{\star+}$ & $965 \pm 207^{*+}$ \\
\hline DMSO & $2083 \pm 176$ & $908 \pm 188^{*+}$ & $900 \pm 190^{*+}$ & $912 \pm 192^{*+}$ \\
\hline
\end{tabular}

Data are reported as means $\pm S D(N=14$ for each group). Sham $=$ time-matched reperfusion; I/R = ischemia/reperfusion; NaHS = sodium hydrosulfide postconditioning; AG490 = specific inhibitor of JAK2; DMSO = dimethyl sulfoxide; HR = heart rate; LVEDP = left ventricular end-diastolic pressure; LVDP = left ventricular developed pressure; $+\mathrm{dp} /$ $\mathrm{dt}=$ intropy; $-\mathrm{dp} / \mathrm{dt}=$ lusitropy. ${ }^{*} \mathrm{P}<0.05 \mathrm{vs}$ baseline (intragroup comparison). ${ }^{+} \mathrm{P}<0.05$ vs Sham; \#P 0.05 vs I/R (intergroup comparison) (repeated measures ANOVA).

was decreased $(\mathrm{P}<0.05)$ in the NaHS group. Compared to the NaHS group, bcl-2 was decreased and bax was increased in the NaHS+AG-490 and AG-490 groups $(P<$ $0.05)$. There were no significant differences between the I/R and NaHS+AG-490 groups or the AG-490 and DMSO groups. 


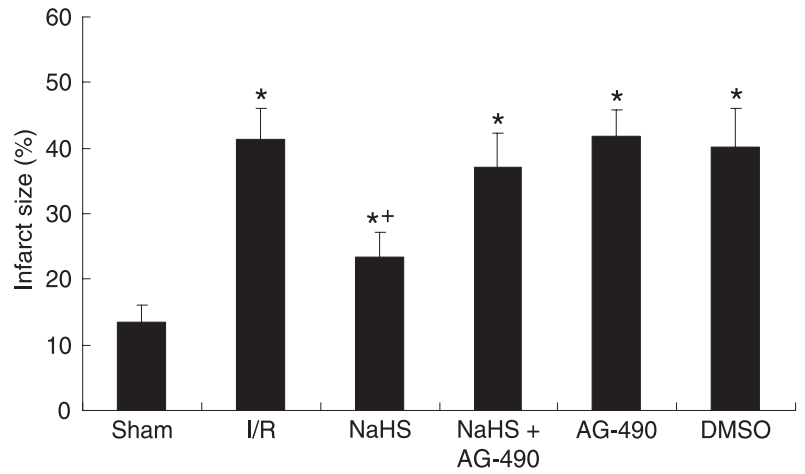

Figure 2. Percent infarct size of the myocardium at the end of reperfusion. Infarct size was determined using 1\% triphenyltetrazolium chloride staining. Eight hearts were used in each group. Data are reported as means $\pm \mathrm{SD}$. ${ }^{*} \mathrm{P}<0.05$ vs Sham; ${ }^{+} \mathrm{P}<0.05$ vs I/R (one-way ANOVA). For abbreviations of groups, see legend to Figure 1.

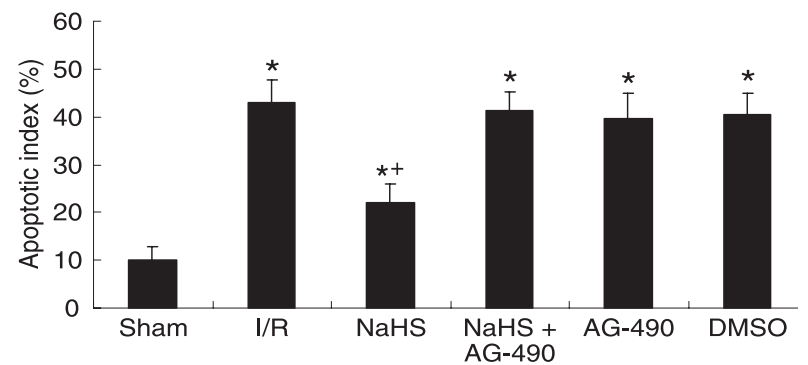

Figure 3. Percentage of TUNEL-positive cells in various groups. Six hearts were used in each group. Data are reported as means $\pm \mathrm{SD}$. ${ }^{*} \mathrm{P}<0.05$ vs Sham; ${ }^{+} \mathrm{P}<0.05$ vs I/R (one-way ANOVA). For abbreviations of groups, see legend to Figure 1.
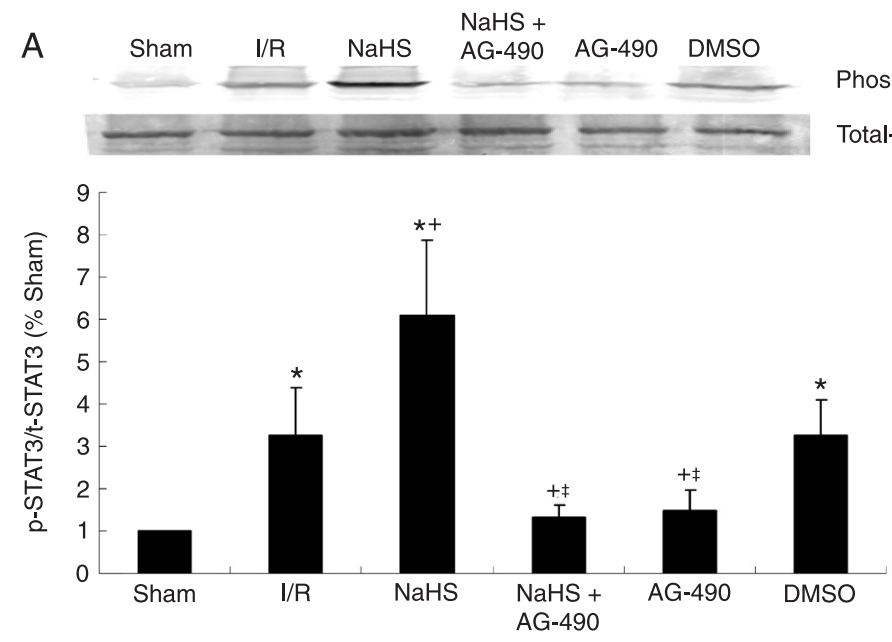

Figure 4. Western blot analysis. The phosphorylation status of STAT3 (86 $\mathrm{kDa})(A)$, bcl-2 (26 kDa) and bax (21 $\mathrm{kDa})(B)$ was analyzed by Western blot with specific phospho-STAT3 (Tyr705), $\mathrm{bcl}-2$ and bax antibodies at the end of reperfusion. Four hearts were used in each group. Data are reported as means $\pm \mathrm{SD}$. ${ }^{*} \mathrm{P}<0.05$ vs Sham; ${ }^{+} \mathrm{P}<$ 0.05 vs I/R; $¥ \mathrm{P}<0.05$ vs NaHS (oneway ANOVA). For abbreviations of groups, see legend to Figure 1.
B

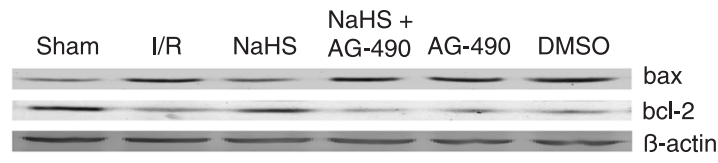

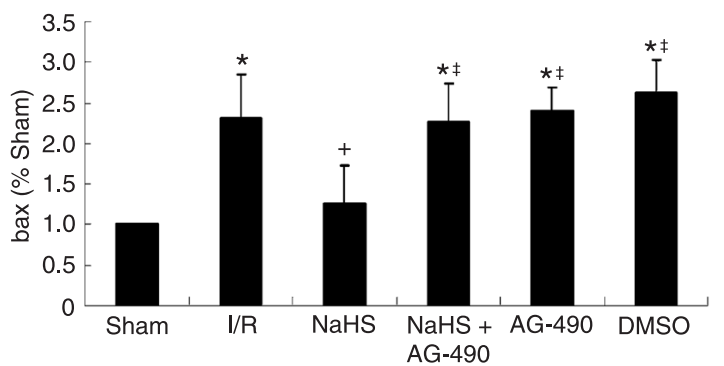

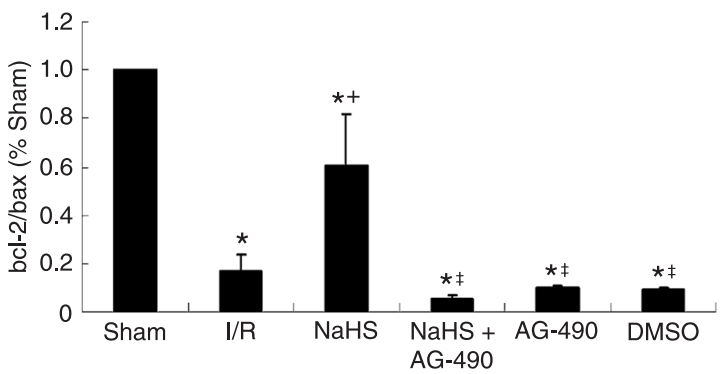




\section{Discussion}

In the heart, $\mathrm{H}_{2} \mathrm{~S}$ is produced in the myocardium, fibroblasts and blood vessels from L-cysteine by the enzyme CSE and exerts an important effect on physiological and pathophysiological processes. A pharmacological and patch-clamp study demonstrated that $\mathrm{H}_{2} \mathrm{~S}$ increased $\mathrm{K}_{\mathrm{ATP}}$-dependent current and induced hyperpolarization in isolated vascular smooth muscle cells (22), indicating that $\mathrm{H}_{2} \mathrm{~S}$ was the unique gasiform KATP channel opener. Our previous studies also found that postconditioning with NaHS could contribute to the recovery of myocardial injury mediated by opening of the KATP channel (23). Previous studies have demonstrated that preconditioning and postconditioning with $\mathrm{H}_{2} \mathrm{~S}$ could activate PI3K/Akt, ERK1/2 and PKC to protect the myocardium against ischemia and reperfusion injury (19). In the present study, we used $\mathrm{NaHS}$ as a source of $\mathrm{H}_{2} \mathrm{~S}$ to investigate whether JAK2/ STAT3 participated in the cardioprotection of exogenous application of $\mathrm{NaHS}$ during early reperfusion in an in vitro rat model. Zhao et al. (18) reported that brief episodes of ischemia/reperfusion applied at the onset of reperfusion could reduce infarct size, preserve vascular endothelial function, decrease polymorphonuclear neutrophil accumulation, and reduce apoptosis, termed as "ischemic postcondition". Since then, numerous studies have been done to clarify the definite mechanism of IPO. So far most of these studies have reached the conclusion that IPO could have a protective effect via activation of the RISK pathway (13). However, Lecour et al. (24) observed that inhibition of $\mathrm{PI} 3 \mathrm{~K} / \mathrm{Akt}$ and ERK1/2 did not abolish the cardioprotection induced by TNF- $\alpha$ postconditioning. Moreover, ischemic postconditioning in pigs is associated with phosphorylation of the RISK protein kinases (Akt, ERK and P70S6K), but inhibiting these kinases with pharmacological agents did not abolish the infarct-sparing effect of IPO (14). In 2009, Lecour (16) first reported that the novel SAFE pathway that involves the activation of JAK and STAT-3 was comparable to the RISK pathway in delineating the potential signal transduction pathway involved in IPO. The growing evidence has convinced the scientific community that $\mathrm{H}_{2} \mathrm{~S}$ could exert cardioprotective effect via activation of the RISK pathway; however, whether $\mathrm{H}_{2} \mathrm{~S}$ postconditioning could also activate the SAFE pathway is still unknown.

The present results showed that $\mathrm{H}_{2} \mathrm{~S}$ postconditioning significantly improved $\mathrm{HR},+\mathrm{dp} / \mathrm{dt}$, $-\mathrm{dp} / \mathrm{dt}$, and LVDP, and reduced LVEDP in the left atrium of the isolated rat heart after reperfusion, indicating that $\mathrm{H}_{2} \mathrm{~S}$ postconditioning could improve the contractile and diastolic functions of the ischemic-reperfused myocardium. Reduction in infarct size is considered to be the "gold standard" for the evaluation of the efficacy of interventions tested. The large reduction of infarct size at the end of reperfusion indicated that $\mathrm{H}_{2} \mathrm{~S}$ postconditioning had a significant effect on cardioprotection.
By examining the Western blot, we observed that $\mathrm{H}_{2} \mathrm{~S}$ postconditioning can cause a significant increase in STAT3 activity, and AG-490, as an inhibitor of JAK2, shut down its activity and offset the protection of $\mathrm{H}_{2} \mathrm{~S}$ postconditioning, confirming that the JAK2/STAT3 pathway plays a crucial role in the cardioprotection induced by $\mathrm{H}_{2} \mathrm{~S}$ postconditioning.

In the heart, the JAK2/STAT3 pathway has been implicated in hypertrophy $(5,25)$, apoptosis and inflammation $(26,27)$. The activation of STAT-3 following acute myocardial infarction was first demonstrated in 2001, when increased phosphorylation of STAT-3 was observed up to $24 \mathrm{~h}$ after ligation of the left coronary artery of rats (28). Mice engineered to express cardiac-specific STAT3 showed a $60 \%$ reduction in infarct size following I/R injury $(28,29)$. Although STAT3-dependent target genes are numerous, these studies suggest that STAT3-mediated cardioprotection might be due to specific up-regulation of the free radical scavengers manganese superoxide dismutase and metallothionein. Hattori et al. (30) reported that inhibition of the JAK2/STAT3 pathway with AG-490 abolished the effect of ischemic preconditioning-induced up-regulation of the antiapoptotic gene bcl-2 and down-regulation of the pro-apoptotic gene bax in an in vitro rat model. Negoro et al. (31) suggested that blocking STAT3 activity with the JAK2 inhibitor AG-490 resulted in increased numbers of TUNEL-positive cells and increased caspase- 3 activity in an in vivo rat model of myocardial infarction. It has been suggested in other studies that, in addition to regulating transcription and translation, phosphorylated STAT3 can inhibit apoptosis by phosphorylating the pro-apoptotic protein BAD (24). Moreover, Gross et al. (32) reported that the JAK2/STAT3 pathway participates in opioid-induced cardioprotection via phosphorylation and inactivation of glycogen synthase kinase $3 \beta$ (GSK-3 $\beta$ ), while phosphorylation and inactivation of GSK-3 $\beta$ are acquired for postconditioning to prevent opening of the mitochondrial permeability transition pore during reperfusion (33). In the present study, after 60 min of reperfusion, we observed that the activity of STAT3 increased in both the I/R and NaHS groups. However, this increase was much more pronounced in the $\mathrm{H}_{2} \mathrm{~S}$ postconditioning group, and AG-490 offset the protection induced by $\mathrm{H}_{2} \mathrm{~S}$ postconditioning, which indicated that JAK2/STAT3 was an important signal path in cardioprotection induced by $\mathrm{H}_{2} \mathrm{~S}$ postconditioning.

A large number of studies indicate that apoptosis plays an important role in myocardial infarction after ischemia (3436). Reduction of apoptosis is achieved by up-regulation of several anti-apoptotic factors including the bcl-2 gene and down-regulation of pro-apoptotic genes such as p53 and bax $(37,38)$. Several studies have suggested that an increase in the bcl-2/bax protein ratio may be important in preventing apoptosis in the myocardium after ischemia and reperfusion $(39,40)$. In the present study, AG-490 was used to inhibit the JAK2/STAT3 pathway in order to examine the physiological function of this pathway in the 
anti-apoptotic effect of $\mathrm{H}_{2} \mathrm{~S}$ postconditioning. Treatment with AG-490 reduced the phosphorylation of STAT3, and resulted in a significant increase in myocardial apoptosis, as demonstrated by the TUNEL assay. Meanwhile, the up-regulation of bcl-2 and down-regulation of bax induced by $\mathrm{H}_{2} \mathrm{~S}$ postconditioning were abolished by AG-490. Thus, our results demonstrated that the JAK2/STAT3 pathway participated in the anti-apoptotic effect of $\mathrm{H}_{2} \mathrm{~S}$ postconditioning, and this effect may be achieved by up-regulating the antiapoptotic protein bcl-2 and down-regulating the pro-apoptotic protein bax. Our results are consistent with the conclusion reached by Hattori et al. (30).

Although JAK2/STAT3 played a very important role in myocardial protection in our study, the mechanisms mediating myocardial protection are unclear. The results also require clarification, because we did not specifically examine the expression of other proteins, which were regulated by activated STAT3, nor did we explore the activities of certain proteins, which were phosphorylated by activated STAT3 in the rat myocardium exposed to ischemia and reperfusion, and the exact components of this signaling pathway need to be clarified. Whether activation of the RISK and SAFE pathways provides an additive effect to maximize cardioprotection needs further research. It is also unknown whether these two pathways converge on the same targets such as the mitochondrial permeability transition pore.

The current results confirm that $\mathrm{H}_{2} \mathrm{~S}$ postconditioning can reduce myocardial infarct size, improve construction and relaxation of the myocardium and reduce the apoptosis index of myocardium in isolated Sprague-Dawley rat hearts with acute myocardial I/R injury. A selective pharmacologi-

\section{References}

1. Dirksen MT, Laarman GJ, Simoons ML, Duncker DJ. Reperfusion injury in humans: a review of clinical trials on reperfusion injury inhibitory strategies. Cardiovasc Res 2007; 74: 343-355.

2. Zhao ZQ, Corvera JS, Halkos ME, Kerendi F, Wang NP, Guyton RA, et al. Inhibition of myocardial injury by ischemic postconditioning during reperfusion: comparison with ischemic preconditioning. Am J Physiol Heart Circ Physiol 2003; 285: H579-H588.

3. Kunisada K, Hirota H, Fujio Y, Matsui H, Tani Y, YamauchiTakihara K, et al. Activation of JAK-STAT and MAP kinases by leukemia inhibitory factor through gp130 in cardiac myocytes. Circulation 1996; 94: 2626-2632.

4. Stephanou A, Brar BK, Scarabelli TM, Jonassen AK, Yellon DM, Marber MS, et al. Ischemia-induced STAT-1 expression and activation play a critical role in cardiomyocyte apoptosis. J Biol Chem 2000; 275: 10002-10008.

5. Kunisada K, Tone E, Fujio Y, Matsui H, Yamauchi-Takihara $\mathrm{K}$, Kishimoto T. Activation of gp130 transduces hypertrophic signals via STAT3 in cardiac myocytes. Circulation 1998; 98 : 346-352.

6. Pan J, Fukuda K, Kodama H, Makino S, Takahashi T, Sano cal inhibitor of JAK2 abolished the cardioprotection of $\mathrm{H}_{2} \mathrm{~S}$ postconditioning, which revealed that the cardioprotective effect of $\mathrm{H}_{2} \mathrm{~S}$ postconditioning was mediated by the JAK2/ STAT3 signaling pathway. The cardioprotective mechanism of $\mathrm{H}_{2} \mathrm{~S}$ is complex, and requires further research.

\section{Study limitations}

In our study, the infarct size in the Sham group was 13.3 $\pm 2.8 \%$, which was a little larger than the sizes obtained by other laboratories. This may have been due to differences in the skill of the operator, the composition of the perfusion fluid and the temperature at which the studies were carried out. Another explanation for this result might be the fact that the isolated heart was removed when the animal was alive, which means that the sympathetic and vagal stimulations no longer existed. In addition, the absence of other peripheral factors such as catecholamines or other neurotransmitters must always be taken into account. However, compared to the Sham group, infarct size in the I/R group was significantly increased $(41.2 \pm 4.7 \%)$, so we could consider the possibility that the effect noted in the I/R group was not accounted for by the global ischemia itself. However, this does not influence the conclusion that $\mathrm{H}_{2} \mathrm{~S}$ postconditioning protects isolated rat hearts subjected to I/R via activation of the JAK2/STAT3 signaling pathway.

\section{Acknowledgments}

Research supported by grants from the Project of the Education Department of Jiangsu Province.
$M$, et al. Role of angiotensin II in activation of the JAK/STAT pathway induced by acute pressure overload in the rat heart. Circ Res 1997; 81: 611-617.

7. Kumar A, Commane M, Flickinger TW, Horvath CM, Stark GR. Defective TNF-alpha-induced apoptosis in STAT1-null cells due to low constitutive levels of caspases. Science 1997; 278: 1630-1632.

8. Chin YE, Kitagawa M, Kuida K, Flavell RA, Fu XY. Activation of the STAT signaling pathway can cause expression of caspase 1 and apoptosis. Mol Cell Biol 1997; 17: 5328-5337.

9. Bolli R, Dawn B, Xuan YT. Emerging role of the JAK-STAT pathway as a mechanism of protection against ischemia/ reperfusion injury. J Mol Cell Cardiol 2001; 33: 1893-1896.

10. Mascareno E, El-Shafei M, Maulik N, Sato M, Guo Y, Das DK, et al. JAK/STAT signaling is associated with cardiac dysfunction during ischemia and reperfusion. Circulation 2001; 104: 325-329.

11. Bolli R, Dawn B, Xuan YT. Role of the JAK-STAT pathway in protection against myocardial ischemia/reperfusion injury. Trends Cardiovasc Med 2003; 13: 72-79.

12. Boengler K, Buechert A, Heinen Y, Roeskes C, HilfikerKleiner D, Heusch G, et al. Cardioprotection by ischemic 
postconditioning is lost in aged and STAT3-deficient mice. Circ Res 2008; 102: 131-135.

13. Hausenloy DJ, Yellon DM. New directions for protecting the heart against ischaemia-reperfusion injury: targeting the Reperfusion Injury Salvage Kinase (RISK)-pathway. Cardiovasc Res 2004; 61: 448-460.

14. Skyschally A, van Caster P, Boengler K, Gres P, Musiolik $J$, Schilawa D, et al. Ischemic postconditioning in pigs: no causal role for RISK activation. Circ Res 2009; 104: 15-18.

15. Schwartz LM, Lagranha CJ. Ischemic postconditioning during reperfusion activates Akt and ERK without protecting against lethal myocardial ischemia-reperfusion injury in pigs. Am J Physiol Heart Circ Physiol 2006; 290: H1011-H1018.

16. Lecour S. Activation of the protective Survivor Activating Factor Enhancement (SAFE) pathway against reperfusion injury: Does it go beyond the RISK pathway? J Mol Cell Cardiol 2009; 47: 32-40.

17. Geng B, Yang J, Qi Y, Zhao J, Pang Y, Du J, et al. $\mathrm{H}_{2} \mathrm{~S}$ generated by heart in rat and its effects on cardiac function. Biochem Biophys Res Commun 2004; 313: 362-368.

18. Zhao W, Zhang J, Lu Y, Wang R. The vasorelaxant effect of $\mathrm{H}_{2} \mathrm{~S}$ as a novel endogenous gaseous K(ATP) channel opener. EMBO J 2001; 20: 6008-6016.

19. Hu Y, Chen X, Pan TT, Neo KL, Lee SW, Khin ES, et al. Cardioprotection induced by hydrogen sulfide preconditioning involves activation of ERK and PI3K/Akt pathways. Pflugers Arch 2008; 455: 607-616.

20. Pan TT, Neo KL, Hu LF, Yong QC, Bian JS. $\mathrm{H}_{2} \mathrm{~S}$ preconditioning-induced $\mathrm{PKC}$ activation regulates intracellular calcium handling in rat cardiomyocytes. Am J Physiol Cell Physiol 2008; 294: C169-C177.

21. Lowry $\mathrm{OH}$, Rosebrough NJ, Farr AL, Randall RJ. Protein measurement with the Folin phenol reagent. $J$ Biol Chem 1951; 193: 265-275

22. Tang G, Wu L, Liang W, Wang R. Direct stimulation of $\mathrm{K}(\mathrm{ATP})$ channels by exogenous and endogenous hydrogen sulfide in vascular smooth muscle cells. Mol Pharmacol 2005; 68: 1757-1764.

23. Ji Y, Pang QF, Xu G, Wang L, Wang JK, Zeng YM. Exogenous hydrogen sulfide postconditioning protects isolated rat hearts against ischemia-reperfusion injury. Eur J Pharmacol 2008; 587: 1-7.

24. Lecour S, Suleman N, Deuchar GA, Somers S, Lacerda L, Huisamen B, et al. Pharmacological preconditioning with tumor necrosis factor-alpha activates signal transducer and activator of transcription-3 at reperfusion without involving classic prosurvival kinases (Akt and extracellular signalregulated kinase). Circulation 2005; 112: 3911-3918.

25. Kunisada K, Negoro S, Tone E, Funamoto M, Osugi T, Yamada S, et al. Signal transducer and activator of transcription 3 in the heart transduces not only a hypertrophic signal but a protective signal against doxorubicin-induced cardiomyopathy. Proc Natl Acad Sci U S A 2000; 97: 315-319.

26. McWhinney CD, Hunt RA, Conrad KM, Dostal DE, Baker KM. The type I angiotensin II receptor couples to Stat1 and
Stat3 activation through Jak2 kinase in neonatal rat cardiac myocytes. J Mol Cell Cardiol 1997; 29: 2513-2524.

27. Sheng Z, Pennica D, Wood WI, Chien KR. Cardiotrophin-1 displays early expression in the murine heart tube and promotes cardiac myocyte survival. Development 1996; 122: 419-428.

28. Negoro S, Kunisada K, Fujio Y, Funamoto M, Darville MI, Eizirik DL, et al. Activation of signal transducer and activator of transcription 3 protects cardiomyocytes from hypoxia/ reoxygenation-induced oxidative stress through the upregulation of manganese superoxide dismutase. Circulation 2001; 104: 979-981.

29. Oshima Y, Fujio Y, Nakanishi T, Itoh N, Yamamoto Y, Negoro $\mathrm{S}$, et al. STAT3 mediates cardioprotection against ischemia/ reperfusion injury through metallothionein induction in the heart. Cardiovasc Res 2005; 65: 428-435.

30. Hattori R, Maulik N, Otani H, Zhu L, Cordis G, Engelman RM, et al. Role of STAT3 in ischemic preconditioning. $J \mathrm{Mol}$ Cell Cardiol 2001; 33: 1929-1936.

31. Negoro S, Kunisada K, Tone E, Funamoto M, Oh H, Kishimoto T, et al. Activation of JAK/STAT pathway transduces cytoprotective signal in rat acute myocardial infarction. Cardiovasc Res 2000; 47: 797-805.

32. Gross ER, Hsu AK, Gross GJ. The JAK/STAT pathway is essential for opioid-induced cardioprotection: JAK2 as a mediator of STAT3, Akt, and GSK-3 beta. Am J Physiol Heart Circ Physiol 2006; 291: H827-H834.

33. Gomez L, Paillard M, Thibault H, Derumeaux G, Ovize M. Inhibition of GSK3beta by postconditioning is required to prevent opening of the mitochondrial permeability transition pore during reperfusion. Circulation 2008; 117: 2761-2768.

34. Penna C, Perrelli MG, Raimondo S, Tullio F, Merlino A, Moro $F$, et al. Postconditioning induces an anti-apoptotic effect and preserves mitochondrial integrity in isolated rat hearts. Biochim Biophys Acta 2009; 1787: 794-801.

35. Yao YT, Fang NX, Shi CX, Li LH. Sevoflurane postconditioning protects isolated rat hearts against ischemia-reperfusion injury. Chin Med J 2010; 123: 1320-1328.

36. Logue SE, Gustafsson AB, Samali A, Gottlieb RA. Ischemia/ reperfusion injury at the intersection with cell death. $J \mathrm{Mol}$ Cell Cardiol 2005; 38: 21-33.

37. Maulik N, Engelman RM, Rousou JA, Flack JE III, Deaton $D$, Das DK. Ischemic preconditioning reduces apoptosis by upregulating anti-death gene Bcl-2. Circulation 1999; 100: II-369-II-375.

38. Maulik N, Sasaki H, Addya S, Das DK. Regulation of cardiomyocyte apoptosis by redox-sensitive transcription factors. FEBS Lett 2000; 485: 7-12.

39. Kuwana T, Newmeyer DD. Bcl-2-family proteins and the role of mitochondria in apoptosis. Curr Opin Cell Biol 2003; 15: 691-699.

40. Degli Esposti M, Dive C. Mitochondrial membrane permeabilisation by Bax/Bak. Biochem Biophys Res Commun 2003; 304: 455-461. 